\title{
O OBJETIVO DE LEITURA EM UMA INTERFACE PSICOLINGUÍSTICA-PRAGMÁTICA**
}

\section{READING PURPOSE IN A PSYCHOLINGUISTICS- PRAGMATICS INTERFACE}

\section{Cláudia Strey*}

\section{RESUMO}

O seguinte artigo objetiva demonstrar a construção de uma possível interface interna entre Psicolinguística e Pragmática a fim de explicar o processo inferencial durante leitura. Para tal, constrói-se uma hipótese de trabalho a partir da observação da realidade: por que os estudantes parecem preferir ler resumos a obras originais? Argumenta-se que essa escolha se dá pelo menor custo cognitivo e não pelo maior benefício, o que vai de encontro ao Princípio Cognitivo proposto pela Teoria da Relevância (SPERBER \& WILSON, 1995). Além disso, o objetivo de leitura e o tipo de avaliação feita parecem interferir na escolha do que é mais relevante (em termos de custo-benefício). Por fim, mostra-se que a interface feita é uma interessante perspectiva teórica para explicar os processos inferenciais envolvidos na leitura.

Palavras-chave: psicolinguística; pragmática; objetivo de leitura.

\section{ABSTRACT}

The following article aims to demonstrate a possible construction of an interface between Psycholinguistics and Pragmatics in order to explain the inferential process in reading. For this purpose, the object of study arises from the observation of reality: high-school students seem to prefer reading summaries than reading the original literary text. We argue that this choice is lead by lower cost and not greatest cognitive benefit, which goes against the Cognitive Principle proposed by Relevance Theory (SPERBER \& WILSON, 1995). Furthermore, the purpose of reading and the type of evaluation might influence the choice of what is more relevant (in terms of effort-benefit). Finally, we show that this interface is an interesting theoretical perspective to explain the inferential processes in reading.

Keywords: psycholinguistics; pragmatics; reading purpose.

\footnotetext{
* PUC-RS, Porto Alegre (RS), Brasil. claudiastrey@yahoo.com.br

** O artigo foi escrito para uma disciplina do PPGL e sua publicação foi em ebook: STREY, C., "A relevância do objetivo de leitura". In: PEREIRA, V. W.; GUARESI, R. (org.). Estudos sobre leitura: psicolinguística e intefaces. Porto Alegre: EDIPUCRS, 2012.
} 


\section{INTRODUÇÃO}

Para que se estabeleça uma definição apropriada do que é leitura, é necessário que se defina a interface ${ }^{1}$ em que se trabalha. Se a área de interface é a Social, podese entender leitura como uma prática de inclusão social, em que se trabalha com conceitos de capacidade crítica e de exercício da cidadania. Se a área é a Cognitiva, leitura passa a ser definida como processo cognitivo, em que se estudam aspectos como inferência, predição, memória. Por fim, se a área de interface é a Ciência Formal, leitura pode ser estudada no sentido de observar como questões lógicas interferem na compreensão leitora.

Neste estudo, o objeto contruído se dará na interface entre Psicolinguística (uma interface entre Linguística e Psicologia) e Pragmática (uma subárea linguística), em que se assumem hipóteses de leitura (SOLÉ, 1998) e de comunicação (Teoria da Relevância - SPERBER \& WILSON, 1995) para derivar conclusões que possam ser interessantes para ambas as áreas envolvidas. $\mathrm{O}$ artigo assume uma hipótese de trabalho que está ancorada em uma observação do atual cenário escolar: atualmente, em relação a obras literárias, os jovens parecem preferir ler resumos a ler os textos originais, fazendo a opção a partir de uma relação entre menor custo e maior benefício.

As perguntas norteadoras emergem dessa hipótese: por que, na escola, a maior parte dos alunos parece ter essa preferência de leitura? Como explicar a diferença de leitura entre esses dois gêneros (obra literária e resumo)? Qual o papel dos objetivos de leitura e da avaliação feita pelos professores? Como a Teoria da Relevância pode ajudar a explicar essa escolha?

Partindo desses questionamentos e do objetivo principal - construir uma interface entre Psicolinguístca e Pragmática -, algumas hipóteses são construídas: (a) o objetivo de leitura e o tipo de avaliação parecem guiar a leitura feita pelos alunos; (b) o princípio da Relevância ajuda a explicar a escolha de qual forma de leitura é mais relevante de acordo com o seu objetivo; (c) a leitura é determinada pelo menor custo cognitivo, e não pelo maior benefício.

$\mathrm{O}$ artigo que se segue está organizado da seguinte forma: primeiro, aborda-se como a leitura pode ser compreendida no aporte teórico da Teoria da Relevância

1. A visão de que o estudo das ciências deve ser feito por meio de interfaces está de acordo com a Metateoria das Interfaces, desenvolvida por Campos (2007), que argumenta que, somente através de interfaces, consegue-se explicar uma maior quantidade de fenômenos adequadamente. Para a Filosofia da Ciência (e, consequentemente, da Linguística), isso implica construir um objeto de acordo com a perspectiva adotada, e não observar um objeto pré-existente a essa perspectiva. 
para, em seguida, mostrar a perspectiva de leitura à luz da Psicolinguística. A terceira e a quarta seção são destinadas à construção da interface: qual o custo cognitivo envolvido na leitura de resumos e de obras literárias, e qual sua relação com os objetivos de leitura e de avaliação escolar. Utilizam-se, como exemplos ilustrativos trechos da obra Iracema, de José de Alencar e de alguns de seus resumos, disponíveis na internet.

\section{DA LEITURA NA PERSPECTIVA DA RELEVÂNCIA}

Após o desenvolvimento de teorias que abordam aspectos pragmáticos da linguagem, a comunicação verbal deixou de ser compreendida apenas como um processo de codificação e de decodificação, baseado no modelo de código (SHANNON e WEAVER, 1949). A comunicação passou a ser entendida como inferencial, em que não somente o dito tem papel fundamental para a compreensão, mas também o implicado. Grice ${ }^{2}$ foi um dos filósofos que mais contribuíram para esse processo, pois reconheceu o papel da intencionalidade e da inferência na comunicação, além de criar um modelo de pesquisa abrangente, capaz de dar estímulos a investigações futuras.

Partindo do modelo griceano, Sperber e Wilson (1995) desenvolvem a Teoria da Relevância, que busca explicar a linguagem na interface entre comunicação e cognição. A Teoria da Relevância é um modelo de comunicação ostensiva, no qual o falante tornará manifesta a sua intenção informativa e comunicativa; e inferencial, em que o ouvinte deverá construir o contexto para chegar à interpretação do enunciado. A teoria fundamenta-se em duas propriedades que não podem ser dissociadas: a ostensão por parte do comunicador e a inferência por parte do receptor.

A ideia principal da teoria, como enfatiza Silveira (2005), está no conceito de Relevância, em que se estabelece uma relação entre custo cognitivo despendido e efeito contextual alcançado. Essa característica refere-se ao fato de que os seres humanos prestam atenção àquilo que lhes parece relevante, desencadeando um processo inferencial. Para tal, Sperber e Wilson (1995) propõem dois princípios: o primeiro é o Princípio Cognitivo: "A comunicação humana tende a ser dirigida para a maximização da relevância" (SPERBER \& WILSON, 1995, p.260). Isso não

2. Grice propôs uma teoria baseada no modelo inferencial de comunicação. Para ele, as inferências resultantes no processo de comunicação são derivadas de um acordo entre falante e ouvinte, chamado de Princípio da Cooperação e ligado a quatro máximas (quantidade, qualidade, relação e maneira). Seus trabalhos mais conhecidos são Meaning (1957) e Logic and Conversation (1975). 
significa dizer que os seres humanos sempre alcançam a relevância máxima (maiores efeitos cognitivos com menores efeitos contextuais), mas, ao contrário, significa que a mente humana possui uma tendência a escolher os estímulos, a ativar o conjunto de informações mais relevantes e a processá-los da maneira mais produtiva.

O segundo princípio fundamental é o Princípio Comunicativo: "Todo estímulo ostensivo comunica a presunção de sua própria relevância ótima" (SPERBER \& WILSON, 1995, p.260). Em relação à noção de relevância ótima, os autores afirmam que um estímulo será otimamente relevante se, e somente se, ele for relevante o suficiente para merecer esforço de processamento da audiência, e o mais relevante compatível com as habilidades e preferências do comunicador.

Outro conceito fundamental da teoria e importante para a interface com a Psicolinguística refere-se à noção de contexto, que não é dado de antemão, mas construído a partir do processo comunicativo. $\mathrm{O}$ contexto pode ser definido como um conjunto de premissas usadas para interpretar um enunciado, que se referem a um subconjunto de crenças do ouvinte sobre o mundo. A seleção do contexto é parte do processo de interpretação, ou seja, as "suposições são acrescentadas a partir do enunciado a ser interpretado, indicando que o contexto não é dado de antemão, mas construído no curso da informação" (SILVEIRA \& FELTES, 2002, p.46).

A partir da noção principal de relevância - relação custo-benefício -, pode-se transpor a comunicação oral para a escrita, e se analisar o processo de leitura através da relação entre ouvinte-leitor e falante-autor. Dessa forma, Silveira e Feltes (2002, p.64) afirmam:

Se, conforme Sperber e Wilson, o papel do ouvinte é tão importante nesse processo [comunicativo], e se o comportamento verbal dos falantes é restringido pela expectativa de Relevância do ouvinte, então, em termos de autor e leitor, tal expectativa deve ser considerada a base para a análise do texto/discurso.

Assume-se, assim, que a leitura também é baseada no princípio inato da Relevância, que parece ser determinante para explicar a comunicação humana. Nessa perspectiva, Campos (2009, p.58-59) afirma que

Ler consiste, essencialmente, num processo de construir cognitivamente uma espécie de código mental a partir de um código escrito, em que de grafemas visuais chegamos a representações isomórficas internas. (...) A noção de composicionalidade sintático-semântica é vital no processo de leitura; é a soma dos fatores mínimos como grafemas em sílabas, palavras e sentenças, tudo dentro de uma certa ordem de boa formação, que gera o processo em pauta. Dizendo de outro modo, ler não é adivinhar, é decodificar e compreender. 
Compreender o texto significa, portanto, ser capaz de produzir inferências relevantes, com o menor custo para maiores efeitos. Como se dá, então, a produção de inferências durante o processo da leitura? Há algum outro fator que pode influenciar a geração de inferências? Qual o papel da predição e das hipóteses construídas ao longo da leitura, por exemplo? Essas perguntas serão tratadas na próxima seção, que abordará a perspectiva Psicolinguística da leitura.

\section{DA LEITURA NA PERSPECTIVA DA PSICOLINGUÍSTICA}

Na maior parte dos estudos de Psicolinguística, a leitura é compreendida como um processo complexo, que ocorre de maneira ascendente (bottom up) ou descendente (top down). A escolha de qual processo será utilizado envolve algumas variáveis, como tipo de texto, objetivo de leitura, conhecimentos prévios do leitor e estilo cognitivo (PEREIRA, 2010).

O modelo ascendente de leitura (bottom up) é o centrado no texto, desenvolvido por Gough (1972), que considera a leitura como um processo linear, serial, que vai da identificação de letras e palavras à extração do significado no texto. A leitura é vista como um processo passivo, no qual o leitor é apenas um decodificador do significado que a própria leitura carrega.

No modelo descendente (top down), proposto por Goodman (1970), o leitor utiliza seus conhecimentos prévios para fazer antecipações e predições sobre o conteúdo do texto, fixando-se para verificá-las. Segundo Solé (1998), esse processo também é hierárquico, embora descendente, pois, a partir de hipóteses e antecipações prévias, o texto é processado para verificação.

Há, no entanto, um terceiro modelo que faz uma síntese dos outros dois enfoques para explicar o processamento da leitura. Segundo a teoria dos esquemas de Rumelhart (1981), o leitor constrói o texto a partir de informações linguísticas (lexicais, sintáticas, semânticas) associadas ao conhecimento de mundo. Os processamentos ascendente e descendente seriam não-excludentes, e aconteceriam simultaneamente ou em paralelo.

A perspectiva assumida neste artigo é que, durante a leitura, é necessário utilizar diferentes estratégias inerentes a cada tipo de processamento. Ou seja, não há predomínio somente de um ou de outro processo, mas a forma como se dá a compreensão depende de níveis de relevância. Além de a decodificação ser imprescindível, é preciso que se assuma a importância do processo inferencial (através de construção de contexto e acesso à memória enciclopédica), de acordo 
com a Teoria da Relevância. A hipótese que se assume é que, independente do processo, a compreensão envolve inferências multiformes ${ }^{3}$, que vão desde inferências fonológicas até inferências pragmáticas.

Assumindo-se a importância do processo inferencial, é importante observar quais outros fatores influenciam na formação de inferências. A Psicolinguística descreve alguns fatores, como o tipo de texto, o objetivo de leitura e os conhecimentos prévios. Em relação aos objetivos de leitura, Solé (1998) afirma que eles determinam como o leitor se situa perante um texto para que haja uma melhor compreensão. Segundo a autora, parece haver um acordo geral de que os bons leitores leem textos diferentes de diferentes maneiras, sendo esse fato um indicador da competência leitora, ou seja, da capacidade de se utilizar distintas estratégias em distintas leituras.

Solé ainda afirma que os objetivos de leitura podem ser muito variados, sendo impossível elencar todos. Entretanto, a autora propõe alguns objetivos genéricos, cuja presença é importante na vida adulta e podem ser trabalhados na escola: (a) ler para obter uma informação precisa; (b) ler para seguir instruções; (c) ler para obter uma informação de caráter geral; (d) ler para aprender; (e) ler para revisar um escrito próprio; (f) ler por prazer; (g) ler para comunicar um texto a um auditório; (h) ler para praticar a leitura em voz alta; (i) ler para verificar o que se compreendeu. (SOLÉ, 1998, p.93-101).

Vários estudos na Psicolinguística abordam a relação entre objetivo de leitura e quantidade e tipos de inferências, como, por exemplo, Narvaez et al. (1999), Vivas (2004), Sponholz, Gerber e Volker (2003), Gerber e Tomitch (2008). A maior parte dos estudos utiliza o Protocolo de Pausa (CAVALCANTI, 1989), em que os informantes devem verbalizar qualquer pensamento que ocorra durante a leitura. Entretanto, deve-se observar que a própria metodologia é passível de questionamento, pois há várias inferências que são praticamente automáticas. Ou seja, ao ler, fazem-se inferências que muitas vezes não são verbalizadas, mas que são de extrema importância para a compreensão de como se dá a leitura.

Para tentar solucionar esse problema, intrínseco aos estudos da Psicolinguística, recente área da Linguística, propõe-se explicar como os objetivos de leitura influenciam na construção das inferências, em uma interface entre a Psicolinguística e a Teoria da Relevância.

3. Inferências multiformes são aquelas que podem ser geradas por diversas fontes (lógicas, lexicais, semânticas, pragmáticas). Para mais detalhes, ver Campos (disponível em bttp://www.jcamposc.com. br/O_Texto_Juridico.pdf) 


\section{DA RELEVÂNCIA DOS OBJETIVOS DE LEITURA: RESUMOS}

De uma maneira geral, observa-se que a leitura de obras clássicas da literatura parece, nas escolas, estar perdendo espaço para a leitura dos resumos das obras. Como explicar essa escolha? Em um primeiro momento, é preciso observar como a leitura está sendo encaminhada na sala de aula, ou melhor, quais objetivos de leitura estão sendo propostos pelos professores. Em um segundo momento, há que se pensar na relação custo-benefício, em que o custo cognitivo (a quantidade de esforço demandada) de ler um clássico, cuja linguagem pode ser muito distante daquela vivenciada pelos jovens, parece ser muito alto para os benefícios (efeitos cognitivos alcançados).

Como explicar a preferência dos jovens em ler os resumos ao invés da obra literária? Ao propor uma leitura, muitos professores objetivam incentivar a leitura de textos literários a fim de se fazer um estudo mais aprofundado. Entretanto, muitas vezes, a avaliação feita parece não ser compatível com a intenção inicial dos professores, pois, ao fazerem questões que abordem apenas as informações gerais do texto, os alunos ajustam sua leitura para que ela seja a mais relevante possível. Dessa forma, a relação objetivo-relevância-avaliação parece ser essencial para explicar a leitura na escola.

Suponha que o objetivo inicial de leitura seja ler para aprender. Segundo Solé (1998), a finalidade desse objetivo é ampliar, de forma explícita, os conhecimentos a partir da leitura de determinado texto. O aluno estará em um processo em que irá estabelecer relações com o que já sabe, rever o que já conhece, formular novas hipóteses. Entretanto, para esse objetivo, o aluno precisa ter claro o que ele deve aprender (SOLÉ, 1998. p.95-96).

O objetivo de ler para aprender pode estar ligado a outro: ler por prazer. O professor pode associar a leitura para um trabalho ao hábito de ler literatura. Solé (1998, p.97) ressalta que

\footnotetext{
(...) seria útil distinguir entre ler literatura só para ler e ler literatura - e aqui tem sentido, por exemplo, que todos os alunos leiam o mesmo fragmento - para realizar determinadas tarefas que, se abordadas adequadamente, não só interferirão no primeiro objetivo, como também ajudarão a elaborar critérios pessoais que permitam aprofundá-lo.
}

Entretanto, apesar de muitos professores terem esses objetivos iniciais, suas avaliações, muitas vezes, supõem outro tipo de leitura, cujo objetivo é ler para obter uma informação de caráter geral. Segundo Solé (1998, p.94), "quando lemos para obter uma informação geral, não somos pressionados por uma busca concreta, nem 
precisamos saber detalhadamente o que diz o texto; é suficiente ter uma impressão, com as ideias mais gerais." Apesar de esse objetivo de leitura ser também essencial para a construção de uma leitura crítica, o desenvolvimento desse objetivo parece não ser devidamente trabalhado na escola.

Outro ponto de discussão é que não parece haver um cuidado para que se desenvolvam estratégias em que o aluno consiga, durante a leitura, perceber o que está relacionado às suas ideias e o que não está, por exemplo. Além disso, essa meta parece estar ligada a textos mais informativos do que literários. Dessa maneira, caso se entenda que o resumo é mais informativo e objetivo do que a obra literária, que possui inúmeras figuras de linguagem e passagens mais sugestivas, pode-se afirmar que ele é mais apropriado para o tipo de avaliação que é feita pelos professores: obter uma informação de cunho mais geral.

O argumento parece simples: se a avaliação feita acerca da obra literária aborda os fatos e se o resumo apresenta-os objetivamente, então os alunos leem os resumos. Mas como explicar cognitivamente que o resumo é mais relevante em termos de custo-benefício?

\section{DO CUSTO COGNITIVO DAS INFERÊNCIAS}

Em termos de relação custo-benefício, se o objetivo de leitura for claro e a avaliação coerente com esse objetivo, a leitura do texto original se justifica. $\mathrm{Ou}$ melhor, o alto custo será compensado com altos efeitos cognitivos, como pode ser visto nas análises a seguir. Observe os textos ${ }^{4}$ abaixo, um trecho do primeiro capítulo de Iracema, de José de Alencar e um resumo desse capítulo, retirado da internet.

4. É importante observar o caráter ilustrativo dos exemplos aqui apresentados, que servem como suporte para o desenvolvimento teórico e não como finalidade metodológica de análise. 


\section{A - Iracema, de José de Alencar}

Três entes respiram sobre o frágil lenho que vai singrando veloce, mar em fora; Um jovem guerreiro cuja tez branca não cora o sangue americano; uma criança e um rafeiro que viram a luz no berço das florestas, e brincam irmãos, filhos ambos da mesma terra selvagem.

A lufada intermitente traz da praia um eco vibrante, que ressoa entre o marulho das vagas:

- Iracema!...

O moço guerreiro, encostado ao mastro, leva os olhos presos na sombra fugitiva da terra; a espaços o olhar empanado por tênue lágrima cai sobre o jirau, onde folgam as duas inocentes criaturas, companheiras de seu infortúnio.

Nesse momento o lábio arranca d'alma um agro sorriso.

Que deixara ele na terra do exílio?

Uma história que me contaram nas lindas várzeas onde nasci, à calada da noite, quando a Lua passeava no céu argenteando os campos, e a brisa rugitava nos palmares.

Fonte: ALENCAR (1866), fragmento.

B - Resumo de Iracema, de José de Alencar

Martim está numa jangada com seu filho e o seu cachorro de estimação. De repente, ele ouve alguém gritar o nome de Iracema e chora.

Fonte: <http://pt.wikipedia.org/wiki/Iracema $>$ fragmento

O Princípio Cognitivo da Relevância (SPERBER e WILSON, 1995, p. 260) postula que a cognição humana tende a ser guiada à maximização da relevância, ou seja, maiores efeitos cognitivos com menores custos cognitivos. Partindo da suposição de que a leitura também é regida pela maximização da relevância, podemse explicar as preferências de leitura dos alunos.

Primeiro, comparar-se-á, em termos de custo-benefício, o texto original (A) com o resumo ${ }^{5}(\mathrm{~B})$. A linguagem do texto de José de Alencar é muito rebuscada, sendo que várias palavras não são usuais e muitas outras são desconhecidas pelos jovens. Consideraremos as duas primeiras frases do fragmento, que fazem parte do primeiro capítulo do livro:

5. Não se trata, aqui, de discutir como o resumo é formado ou qual sua relação com a obra original em termos de escrita. Trata-se apenas da leitura, em que se compara o resumo com um outro texto, no caso literário. 
Três entes respiram sobre o frágil lenho que vai singrando veloce, mar em fora;

Um jovem guerreiro cuja tez branca não cora o sangue americano; uma criança e um rafeiro que viram a luz no berço das florestas, e brincam irmãos, filhos ambos da mesma terra selvagem.

Provavelmente, para que se consiga decodificar (note que essa é uma primeira parte do processo de compreensão), é necessário buscar na memória enciclopédica informações lexicais sobre o que significa, por exemplo, ente, lenbo, tez, singrando, rafeiro, o que já implica certo custo cognitivo. Entretanto, caso o leitor não conheça essas palavras, provavelmente terá que procurá-las no dicionário, o que irá aumentar consideravelmente o custo cognitivo.

Após a decodificação, parte-se para a construção da explicatura e da implicatura $^{6}$ :

- Dito (após a decodificação): Três entes (seres) respiram sobre o frágil lenho (barco de madeira) que vai singrando (navegando) veloce, mar em fora. Um jovem guerreiro cuja tez (pele) branca não cora o sangue americano; uma criança e um rafeiro (cachorro) que viram a luz (nasceram) no berço das florestas, e brincam irmãos, filhos ambos da mesma terra selvagem.

- Explicatura: Três seres (jovem guerreiro, criança e cachorro) respiram sobre o frágil barco que vai navegando veloz, mar em fora. Um jovem guerreiro (Martim) cuja pele branca não cora o sangue americano (dele); uma criança (Moacir) e um cachorro que nasceram no berço das florestas (no Brasil), e brincam irmãos, filhos ambos da mesma terra selvagem.

- Premissas Implicadas:

S1: Três seres estão no mar viajando de barco: duas pessoas e um cachorro.

S2: O jovem guerreiro não é brasileiro.

S3: O jovem guerreiro estava lutando no Brasil.

S3: A criança e o cachorro nasceram no Brasil.

Conclusão implicada 1: Jovem guerreiro, criança e cachorro estavam no Brasil e estão indo embora de barco.

O que pode ser visto nessa passagem é que o custo cognitivo é alto, principalmente por causa da decoficação (palavras desconhecidas) e do

6. Segundo Sperber \& Wilson (1995, p.182), entre o código (ou dito) e aquilo que é implicado, está a explicatura, proposição explicitamente comunicada e base para raciocínios inferenciais. Parte-se das explicaturas para as implicaturas, que se desdobram em premissas e conclusões implicadas. 
processamento sintático, semântico e pragmático. Entretanto, os efeitos cognitivos são altos, também, pois há várias premissas e suposições implicadas.

Observado o processo inferencial necessário para que se compreenda a primeira passagem da obra literária, passa-se para a análise do resumo do capítulo em que o fragmento está localizado (B):

Martim está numa jangada com seu filho e o seu cachorro de estimação. De repente, ele ouve alguém gritar o nome de Iracema e chora.

O processo de decodificação parece ser automático, pois não há palavras desconhecidas. Esse custo cognitivo é, portanto, praticamente nulo. Passa-se a analisar o processo inferencial, com a construção da explicatura e da implicatura.

- Explicatura: Martim está numa jangada com seu filho (de Martim) e com seu cachorro (de Martim). De repente, ele (Martim) ouve alguém gritar o nome de Iracema e (Martim) chora.

- Premissas Implicadas:

S1: Martim tem um filho e um cachorro (por acarretamento).

S2: Martim, seu filho e seu cachorro estão viajando.

S3: Martim sente saudade de Iracema (acessado pelo léxico chora).

Conclusão Implicada: Martim não queria deixar Iracema.

É preciso observar que, nesse resumo, não aparece a descrição de quem são Martim e Iracema, o que faz com que, caso o leitor não saiba quem são as personagens, busque essa informação, o que levará a um maior custo cognitivo.

Ao comparar o processo inferencial de um trecho do primeiro capítulo com o seu resumo, percebe-se que:

- a quantidade de esforço mental exigido pelo texto original é alta, pois os léxicos não são usuais, o que compromete, de certa maneira, o processamento sintático e semântico;

- não há quase esforço cognitivo no processamento do resumo, pois as informações são ditas, não implicadas, ou seja, quase não há necessidade de inferências;

- há mais efeitos cognitivos no texto original, pois se derivam mais implicaturas, como a de que o jovem guerreiro não é brasileiro e a criança e o cachorro são - algo que não é implicado no resumo; 
- a primeira frase do resumo corresponde ao trecho analisado da obra literária em que as implicaturas são do tipo acarretamento (nota-se que a informação de que o jovem guerreiro e a criança são parentes não é possível de ser derivada no trecho observado. Somente após a leitura de toda a obra, pode-se fazer essa inferência, pois o primeiro capítulo corresponde ao último acontecimento da narrativa);

- poder-se-ia afirmar, segundo os princípios da Teoria da Relevância, que ler a obra original é mais relevante, pois há mais efeitos do que custos cognitivos.

Entretanto, mesmo que na perspectiva da Teoria da Relevância a leitura do texto original seja mais relevante, como explicar que os jovens prefiram ler o resumo? Essa resposta pode ser dada caso se considere o objetivo de leitura e, consequentemente, a avaliação feita dessa leitura. Para tal, considerar-se-á a análise ilustrativa entre um resumo da obra (C) e uma questão de vestibular (D).

\section{C - Resumo de Iracema, de José de Alencar}

Lenda criada por Alencar, Iracema explica poeticamente as origens de sua terra natal. A 'virgem dos lábios de mel' tornou-se símbolo do Ceará, e o filho Moacir, nascido de seu amor com o colonizador branco Martim, representa o primeiro cearense, fruto da integração das duas raças. Em Iracema, a relação amorosa entre a jovem índia e o fidalgo português Martim, domina toda a obra. Toda a força poética do livro advém dessa relação amorosa; os demais, a saber, a natureza, a bravura selvagem, a lealdade do índio etc., são elementos já tratados em O Guarani e posteriormente em Ubirajara. Por outro lado, a ação é reduzidíssima, o que dá ao livro um notável espaço lírico de que se valeu Alencar para escrever sua obra mais poética. A desorientação inicial de Martim, jovem fidalgo português, que se perdera nas matas, o surpreendente encontro com a jovem índia, a hospitalidade do selvagem brasileiro, o ciúme do guerreiro, o amor entre os representantes das duas raças - Iracema e Martim, a rivalidade entre as tribos tabajara e potiguara, a nostalgia de Martim por sua terra natal, suas viagens e a tristeza de Iracema com a mudança inesperada de seu amado, o nascimento de Moacir, filho de dor, e a morte de Iracema. Essa é praticamente a síntese da fábula do livro.

Destaca-se, nesta obra, a linguagem bem elaborada de Alencar. O estilo é artisticamente simples, procurando recriar a poesia natural da fala indígena, plena de comparações e personificações, o que dá ao livro as características de um verdadeiro poema.

Fonte: <http://www.algosobre.com.br/resumos-literarios/iracema.html> 
D - Questão de vestibular

(UFU-MG/2001) Sobre Iracema, de José de Alencar, podemos dizer que:

1) As cenas de amor carnal entre Iracema e Martim são de tal forma construídas que o leitor as percebe com vivacidade, porque tudo é narrado de forma explícita.

2) Em Iracema temos o nascimento lendário do Ceará, a história de amor entre Iracema e Martim e as manifestações de ódio das tribos tabajara e potiguara.

3) Moacir é o filho nascido da união de Iracema e Martim. De maneira simbólica ele representa o homem brasileiro, fruto do índio e do branco.

4) A linguagem do romance Iracema é altamente poética, embora o texto esteja em prosa. Alencar consegue belos efeitos lingüísticos ao abusar de imagens sobre imagens, comparações sobre comparações (sic).

Assinale:

(A) se apenas 2 e 4 estiverem corretas.

(B) se apenas 2 e 3 estiverem corretas.

(C) se 2, 3 e 4 estiverem corretas.

(D) se 1,3 e 4 estiverem corretas.

Fonte: DESTRO, I. O CPV ajuda a ler FUVEST, UNICAMP e PUC 2007. São Paulo: CPV Editora, 2007.

A questão de vestibular envolve conhecimentos gerais sobre a obra literária, ou seja, é necessário que o leitor/aluno tenha um conhecimento amplo sobre o que a obra representa, sua história e seus personagens. Não há necessidade de conhecer os detalhes, as inferências vagas veiculadas pelo dito. Isso significa que, se o aluno tiver como objetivo de leitura obter uma informação de caráter geral (SOLÉ 1998, p.94), ele poderá ler somente o resumo, que, como visto anteriormente, possui uma linguagem mais direta e um menor custo cognitivo.

Certamente, para responder à questão, são necessárias diferentes inferências e relações com o que foi lido. Entretanto, o resumo é mais objetivo e aborda aspectos amplos da obra, enquanto a obra em si possui uma linguagem não usual, em que o próprio processo de decodificação já demanda um alto custo cognitivo. O resumo, assim, é suficiente para responder à questão, sem que haja necessidade da leitura da obra literária (e maior esforço de processamento), como pode ser visto na tabela ilustrativa a seguir: 
Tabela 1. Cruzamento entre questão de vestibular e resumo da internet.

\begin{tabular}{|c|c|}
\hline Questão & Trecho do Resumo \\
\hline $\begin{array}{l}\text { 1) as cenas de amor carnal entre Iracema e } \\
\text { Martim são de tal forma construídas que o leitor as } \\
\text { percebe com vivacidade, porque tudo é narrado de } \\
\text { forma explícita. }\end{array}$ & Não há correspondência com o resumo \\
\hline $\begin{array}{l}\text { 2) em Iracema temos o nascimento lendário } \\
\text { do Ceará, a história de amor entre Iracema e Martim } \\
\text { e as manifestações de ódio das tribos tabajara e } \\
\text { potiguara. }\end{array}$ & $\begin{array}{l}\text { - A 'virgem dos lábios de mel' tornou-se símbolo } \\
\text { do Ceará, e o filho Moacir, nascido de seu amor com } \\
\text { o colonizador branco, Martim representa o primeiro } \\
\text { cearense, fruto da integração das duas raças. } \\
\text { - a rivalidade entre as tribos tabajara e potiguara }\end{array}$ \\
\hline $\begin{array}{l}\text { 3) Moacir é o filho nascido da união } \\
\text { de Iracema e Martim. De maneira simbólica ele } \\
\text { representa o homem brasileiro, fruto do índio e do } \\
\text { branco. }\end{array}$ & $\begin{array}{l}\text { - A 'virgem dos lábios de mel' tornou-se símbolo } \\
\text { do Ceará, e o filho Moacir, nascido de seu amor com } \\
\text { o colonizador branco, Martim representa o primeiro } \\
\text { cearense, fruto da integração das duas raças. }\end{array}$ \\
\hline $\begin{array}{l}\text { 4) a linguagem do romance Iracema é } \\
\text { altamente poética, embora o texto esteja em prosa. } \\
\text { Alencar consegue belos efeitos linguísticos ao abusar } \\
\text { de imagens sobre imagens, comparações sobre } \\
\text { comparações }\end{array}$ & $\begin{array}{l}\text { - Destaca-se, nesta obra, a linguagem bem } \\
\text { elaborada de Alencar. } 0 \text { estilo é artisticamente simples, } \\
\text { procurando recriar a poesia natural da fala indígena, } \\
\text { plena de comparações e personificações, o que dá ao } \\
\text { livro as características de um verdadeiro poema. }\end{array}$ \\
\hline
\end{tabular}

Ao fazer uma análise entre os dois fragmentos, percebe-se que o resumo é suficiente para responder à questão. Ou seja, para uma questão cujo objetivo é verificar aspectos gerais do texto, o objetivo de leitura também será esse: lê-se para ter uma ideia ampla do assunto. Caso houvesse questões que necessitassem de uma leitura com o objetivo de ler para aprender ou, até mesmo, ler literatura, talvez a leitura da obra literária compensasse.

Algumas considerações podem ser feitas:

- apesar de, segundo os princípios da Relevância, a obra literária ser mais relevante (maior custo, mas maior benefício), na realidade escolar, os resumos são mais lidos, pois estão relacionados a aspectos gerais do texto, assim como à maior parte das avaliações;

- nesse contexto, o resumo parece ser mais relevante, pois não haveria necessidade de tantos efeitos cognitivos. Em um outro momento escolar, talvez a obra literária fosse mais relevante.

Essas constatações, no entanto, trazem um grande problema para a Teoria da Relevância: a cognição humana parece ser dirigida pelo baixo custo, e não pelo impacto do maior benefício. Isso significa que a leitura de obra literária, exigida em 
sala de aula, muitas vezes, implica um custo cognitivo muito alto, que, apesar de gerar mais benefícios, não compensa. $\mathrm{O}$ resumo, porém, que apresenta menos benefícios, possui um custo também mais baixo. Para que a leitura da obra literária compense (ou seja, o alto custo seja compensado) na realidade escolar, há necessidade de um benefício externo que também compense, como, por exemplo, ir bem em uma prova, ou passar no vestibular (lembrando que para isso ocorrer, é necessário que a prova seja elaborada de forma a compensar o custo). Assim como afirma Costa (2005), o princípio da inércia parece se impor, e não somente em momentos de lazer, mas também de estudo.

A maior parte dos alunos, portanto, parece despender energia cognitiva até que determinado objetivo seja alcançado. Se uma inferência resolve a questão proposta, para que concentrar esforços em duas?

\section{CONSIDERAÇÕES FINAIS}

Este artigo buscou demonstrar a necessidade de construção de interfaces na Linguística para que se compreenda um objeto de estudo de forma diferenciada. $\mathrm{Na}$ interface entre Psicolinguística e Pragmática, procurou-se mostrar que a leitura feita por estudantes do Ensino Médio parece ser guiada pelo menor custo cognitivo, aliado ao objetivo de leitura e ao tipo de avaliação feito.

Levando em consideração que o estudo em interface deve ser feito de forma a gerar impactos nas áreas envolvidas, pode-se afirmar que o artigo trouxe um importante questionamento para a Teoria da Relevância: a mente humana parece não ser guiada pelo maior benefício, mas pelo menor custo, o que traria problemas para o Princípio Cognitivo da Relevância. Além disso, pode-se questionar sobre o que é benefício, pois, em situações de sala de aula, ele parece não ser cognitivo, mas altamente real e objetivo (ir bem na prova, por exemplo).

Em relação à Psicolinguística, uma das contribuições do artigo encontrase no fato de que outra variável parece ser essencial para saber como se dá o processamento de leitura em situações de sala de aula. Além do tipo de texto, conhecimentos prévios e objetivo de leitura, o tipo de avaliação da leitura também precisa ser considerado. Como demonstrado, o leitor (e estudante) irá definir o modo como a leitura será feita de acordo com o que ele espera da avaliação. Cabe ao professor, assim, direcionar a avaliação de acordo com o objetivo de leitura que ele quer (obter informação geral, aprender). 
O objetivo central do trabalho - a construção da interface - foi essencial para que o estudo pudesse ser feito. Sem a perspectiva de uma ou de outra área, talvez os resultados não fossem tão elucidativos para o problema construído. Dessa forma, o que se apresentou não foi uma verdade absoluta sobre o objeto, mas uma perspectiva teórica interessante e que merece mais estudos e aprofundamentos.

\section{REFERÊNCIAS BIBLIOGRÁFICAS}

ALENCAR， J. (1866) Iracema. Disponível em <http://www.dominiopublico.gov.br/ download/texto/bn000014.pdf>. Acesso em 25 de novembro de 2010.

CAMPOS, J. (2007) Ciências da Linguagem: Comunicação, Cognição e Computação Relações Inter/Intradisciplinares. In: AUDY, J. L. N. \& MOROSINI, M. C. (orgs.) Inovação e Interdisciplinaridade na Universidade. Porto Alegre: EDIPUCRS.

. Leitura, cognição e inferência (2009). IN: PEREIRA, V. W.; SILVA, A. J. (et al.). Leitura e cognição: teoria e prática nos anos finais do ensino fundamental. Porto Alegre: EDIPUCRS.

. (2010) O texto jurídico. Disponível em <http://www.jcamposc.com.br/O_Texto Juridico.pdf $>$. Acesso em 10 de novembro de 2010.

CAVALCANTI, M. C. (1989) Interação leitor-texto: aspectos de interpretação pragmática. Campinas: UNICAMP.

COSTA, J. C. da. (2005) A teoria da relevância e as irrelevâncias da vida cotidiana. Linguagem em (dis)curso - Teoria da Relevância. Editora Unisul, v. Esp., n. 5.

DESTRO, I. (2007) O CPV ajuda a ler FUVEST, UNICAMP e PUC 2007. São Paulo: CPV Editora.

GERBER, R. M. \& TOMITCH, L. M. (2008) Leitura e cognição: propósitos de leitura diferentes influem na geração de inferências? Acta Scientiarum Language and Culture.

GOODMAN, K.S. (1970) Reading as a psycholinguistic guessing game. In SINGER, H. \& RUDELL, R.B. (eds.) Theoretical Models and Processes of Reading. Newark: International Reading Association.

GOUGH, P. B. (1972) One second of reading. In: KAVANAGH, J.F. \& MATTINGLY, I.G.(orgs). Language by ear and by eye. Cambridge: MIT Press, p.353-378.

GRICE, P. (1957) Meaning. IN: GRICE, P. Studies in the Way of Words. Cambridge: Harvard University Press, 1989.

. (1975) Logic and Conversation. In: DAVIS, S. Pragmatics. New York: Oxford University Press, 1991. p. 305-315.

IRACEMA. In: Wikipedia. 2010. < http://pt.wikipedia.org/wiki/Iracema >. Acesso em 25 de novembro de 2010.

.In: Algo sobre. 2010 Disponível em <http://www.algosobre.com.br/resumos-literarios/ iracema.html>. Acesso em 25 de novembro de 2010. 
NARVAEZ, D. et al. (1999) The influence of reading purpose on inference generation and comprebension in reading. Arlington: J. Educ. Psychol., v. 91, n. 3, p. 488-496.

PEREIRA, V. W. (2010) Aprendizado da leitura e consciência linguística. IN: Anais do IX Encontro do CELSUL. Palhoça: UNISUL.

RUMELHART, D.E. (1981) Schemata: the building blocks of cognition. In: GUTHRIE, J.T. (ed.). Comprehension and teaching: research reviews. Newark: International Reading Association, p. 3-26.

SHANNON, C. E.; \& WEAVER, (1949) Wr. The Mathematical Theory of Communication. Urbana, University of Illinois Press.

SILVEIRA, J. R. C. (2005) A imagem: interpretação e comunicação. Linguagem em (Dis)curso UNISUL, v. especial, n. 5, p.113-128.

SILVEIRA, J. \& FELTES, H. (2002) Pragmática e cognição: a textualidade pela relevância e outros ensaios. 2 ed. Porto Alegre: EDIPUCRS, 156 p.

SOLÉ, Isabel. (1998) Estratégias de leitura. 6.ed. Porto Alegre: Artmed.

SPERBER, D.; WILSON, D. (1995) Relevance: communication and cognition. 2. ed. Cambridge, USA: Blackwell.

SPONHOLZ, I.; GERBER, R. M. \& VOLKER, T. B. (2003) Propósito de leitura e tipo de texto na geração de inferências. Revista Letra Magna, ano 03, n.05.

VIVAS, G.P.M. (2004) Diferencias en el tipo de inferencias generadas dependiendo del propósito de la lectura: estudiar o criticar. Disponível em: <http://www.fedap.es/congreso_santiago/trabajos/ c154.htm >. Acesso em 15 de novembro de 2010.

Recebido: 13/01/2010

Aceito: 12/04/2011 